See discussions, stats, and author profiles for this publication at: https://www.researchgate.net/publication/326250541

\title{
Public Relations and Advertising in the Context of E-Sports
}

Chapter · July 2018

DOI: 10.4018/978-1-5225-4047-2.ch005

CITATIONS

0

3 authors, including:

Tina Tomazic

Faculty of Electrical Engineering and Computer Science

10 PUBLICATIONS 7 CITATIONS

SEE PROFILE

Some of the authors of this publication are also working on these related projects:

Project $\quad$ Flexicurity View project

Project $\quad$ PAULINA ROJEK ADAMEK From Relational Space to Engagement-Designers' Ethics and Responsibility in the Light of Empirical Research View project
READS

58

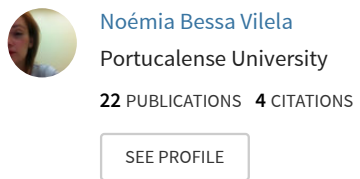




\title{
Chapter 5 \\ Public Relations and Advertising in the Context of E-Sports
}

\author{
Tina Tomazic \\ University of Maribor, Slovenia \\ Luka Druks \\ University of Maribor, Slovenia \\ Noemia Bessa Vilela \\ Universidade Portucalense (UPT), Portugal
}

\begin{abstract}
E-sports within the gaming industry characterize an economic sector that is engaged in the developing, marketing, and sale of video games. They represent many opportunities for advertising and public relations, which are very important to increase the visibility of e-sports. The use of both has proved far more effective, because it allowed a rapid increase in their popularity. The aim of this chapter is to compare the use of public relations and advertising in e-sports and to determine their appropriateness. So, the relationship between public relations, advertising, and e-sports is developed and researched for the first time here. The authors used qualitative comparative analysis between public relations and advertising in the context of e-sports based on Natus Vincere, one of the most important Ukrainian organizations in the gaming industry. The rise of the gaming industry and recent success of e-sports demonstrate the profitable economic potentials of gaming spectatorship.
\end{abstract}

\section{INTRODUCTION}

Videogames are one of the fastest growing media industries worldwide, and playing video games is a form of expression. Hutchins (2008) showed, that the extraordinary global growth of the computer games industry and gaming activities and cultures over the past decade are representative of the speed and character of social and cultural transformation in the second modernity. The World Cyber Games (WCG) represents a logical yet radical extension, integrating the organizational, physical and technological bases of competition. This arrangement has been made possible by the Information Technology (IT) revolution

DOI: $10.4018 / 978-1-5225-4047-2 . c h 005$

Copyright $\odot$ 2019, IGI Global. Copying or distributing in print or electronic forms without written permission of IGI Global is prohibited. 
and rapid expansion in the availability, capabilities and popularity of interactive digital communications technologies. Changes in the scale and capacity of transport and communications technologies, as well as the interrelated standardization and codification of pre-sport pastimes, created fundamental transformations in the structure and appearance of both. Unusually, modern media and sport were born.

The aim of this work is to compare the use of public relations and advertising in the "gaming" industry and e-sports. In this article, the relationship between public relations, advertising and e-sports is developed and researched for the first time. Namely, the gaming industry represents an economic sector that is engaged in the developing, marketing and sale of videogames. A further objective is to present the organization Natus Vincere (NV), one of the most important Ukrainian organizations in the field of the gaming industry and, in the latter case, to determine the appropriateness of the use of public relations and advertising in e-sports. The advertising and public relations was presented in one of the most successful e-sport organizations in the world. The advertising is mainly for insight into the advertising sponsors of NV and advertising the organization as a brand (e.g. selling T-shirts). The authors looked at how public relations work within the e-sports organization NV, and how effective they are. the Qualitative comparative analysis was used to analyze the causal contribution between public relations and advertising to find the crucial differences and to determine which logical conclusions a data set supports in the context of e-sports in the example of the NV organization.

The main limitation is the fact that there are very few scientific papers on the topic of advertising and public relations in e-sports. It is supposed that the advertising in e-sports must become suitable and effective, so that more frequent use of public relations will bring e-sports growing popularity and, thus, the more frequent occurrence of traditional media (the example is South Korea).

It has been considered, that advertising is more suitable and effective than public relations or publicity in e-sports. Due to the poor visibility of e-sport in most countries around the world, this is also a reason for the poor publicity and lack of interest of traditional media for the transmission of e-sports events. In some countries, such as South Korea, e-sports have almost the status of traditional sports, such as football. It is also believed that the application of public relations in the e-sports would contribute to the increasing popularity of e-sports and, therefore, the breakthrough in the traditional media. This applies to the regions or continents (for example Europe), in which e-sports are not so well known or popular.

\section{DEVELOPMENT OF E-SPORTS}

Taylor (2012) argued, that e-sports represent an increasingly popular and profitable array of organizations, communities, and sets of practices, all of which place tremendous value on audiences; for example, playing games competitively, in front of a crowd, represents the legitimization of gaming as a spectator sport. E-sports involve the enactment of videogames as a spectator-driven sport, carried out through promotional activities.

Hutchins (2008) and Taylor (2015) showed, that electronic sport (e-sport), or sport as media, signifies the seamless interpenetration of media content, sport and networked information and communications technologies, and represents an increasingly popular and profitable range of communities, organizations, and sets of practices, all of which place tremendous value on audiences; for example, playing games competitively, in front of a crowd, represents the legitimization of gaming as a spectator sport. However, organized competitive gaming is treated as much more than a passing fad; instead representing the emergence of a new phenomenon, e-sport. 
10 more pages are available in the full version of this document, which may

be purchased using the "Add to Cart" button on the product's webpage:

www.igi-global.com/chapter/public-relations-and-advertising-in-the-context-ofe-sports/207919?camid=4v1

This title is available in InfoSci-Books, Communications, Social Science, and Healthcare, InfoSci-Media and Communications, InfoSci-Social Sciences and Humanities, Advances in Human and Social Aspects of Technology Book Series. Recommend this product to your librarian: www.igi-global.com/e-resources/library-recommendation/?id=1

\section{Related Content}

Sixth Sense Technology: Advances in $\mathrm{HCl}$ as We Approach 2020

Zeenat AlKassim and Nader Mohamed (2017). International Journal of Virtual and Augmented Reality (pp. 18-41).

$\underline{\text { www.igi-global.com/article/sixth-sense-technology/188479?camid=4v1a }}$

Grid Computing for Social Science

Kenneth J. Turner, Paul Lambert, K. L. Tan, Vernon Gayle, Richard O. Sinnott, Ken Prandy, Erik Bihagen and Marco H.D. van Leeuwen (2008). Encyclopedia of Networked and Virtual Organizations (pp. 643-651). www.igi-global.com/chapter/grid-computing-social-science/17671 ?camid=4v1a

Teaching and Learning Abstract Concepts by Means of Social Virtual Worlds David Griol and Zoraida Callejas (2017). International Journal of Virtual and Augmented Reality (pp. 29-42). www.igi-global.com/article/teaching-and-learning-abstract-concepts-by-means-of-social-virtualworlds/169933?camid=4v1a

Preparing for the Forthcoming Industrial Revolution: Beyond Virtual Worlds Technologies for Competence Development and Learning Albena Antonova (2017). International Journal of Virtual and Augmented Reality (pp. 16-28). www.igi-global.com/article/preparing-for-the-forthcoming-industrialrevolution/169932?camid=4v1a 